from their implications for attempted syntheses of the L-shaped double alley and differential conditioning literatures. As previously noted (McHewitt et al, 1969), the assertion that the procedures used and the behavioral effects obtained in double-alley studies are analogous to differential conditioning contrast effects is seemingly contradicted by at least one set of data. Thus, in the double alley, speeds to large reward in the second alley $(\mathrm{S}+)$ decrease as the reward magnitude received in the first alley ( $\mathrm{S}-$ ) increases (Daly, 1968), while in differential conditioning studies speeds to $\mathrm{S}+$ decrease as $\mathrm{S}$ - reward decreases (MacKinnon, 1967; Matsumoto, 1965). On the basis of the present data, this apparent disparity does not appear to reflect any basic difference between the two situations. Rather, the apparent positive $\mathrm{S}+$ contrast observed in the double alley also occurs in discrimination situations when the measurement trial follows, at short ITI, an S- trial, as is the case in the typical double-alley study. The present data indicate that this apparent $\mathrm{S}+$ contrast results from the effect of reward amount on the trial preceding the measurement trial such that $\mathrm{S}+$ speeds vary inversely with reward amount on the preceding trial. It should be noted that just such an effect must be assumed to operate in the double alley in order to account for some behavioral phenomena not

attributable to contrast effects, e.g., the five trials per day for 8 days. All Ss frustration effect, or FE (cf. McHose, in received $.5 \mathrm{ml}$ of $16 \%$ sucrose solution in press).

\section{REFERENCES}

DALY, H. B. Excitatory and inhibitory effects of complete and incomplete reward reduction in the double alley. Journal of Experimental Psychology, 1968, 76, 430-438.

HENDERSON, K. Within-subjects partial-reinforcement effects in acquisition and in later discrimination learning. Journal of Experimental Psychology, 1966, 72, 704-713.

MacKINNON, J. R. Interactive effects of two rewards in a differential magnitude of reward discrimination. Journal of Experimental Psychology, 1967, 75, 329-338.

MATSUMOTO, R. Relative reward effects in differential conditioning. Unpublished doctoral dissertation, University of Iowa, 1965.

McHEWITT, E. R., CALEF, R. S., MAXWELL, F. R., MEYER, P. A., \& MCHOSE, J. H. Synthesis of double alley and discrimination phenomena: Apparent positive $S+$ contrast in differential conditioning. Psychonomic Science, 1969, 16, 137-139.

McHOSE, J. H. Relative reinforcement effects: $S_{1} / S_{2}$ and $S_{1} / S_{1}$ paradigms in instrumental conditioning. Psychological Review, in press. McHOSE, J. H., \& LUDVIGSON, H. W. Role of reward magnitude and incomplete reduction of reward magnitude in the frustration effect. Journal of Experimental Psychology, 1965, $70,490-495$.

\section{NOTES}

1. Supported by Research Grant MH 10340 from the United States Public Health Service.

2. Now at Washington State University, Pullman, Wash. 99163.

\title{
A facilitating effect of latent extinction: Further evidence
}

\section{ELVIS C. JONES, Frostburg State College, Frostburg, Md. 21532, and DONALD SYTSMA and CECIL C. BRIDGES, JR., Texas Christian University, Ft. Worth, Tex. 76129}

An earlier article reported that one $30-\mathrm{sec}$ nonreinforced goal placement resulted in a facilitation of subsequent runway performance. The present experiment indicated that the effect was reliable, but it greatly modified the interpretation offered in the earlier article.

Although direct, nonreinforced placements in a goalbox (latent extinction placements) usually result in a decrement in runway performance, Jones, Narver, \& Bridges (1967) found that one 30-sec latent extinction placement resulted in a facilitation of subsequent runway performance. The effect was attributed to an increase in frustration after frustration had become attached to the running response as a result of training on a partial reinforcement schedule. The present experiment attempted to determine if the effect would be obtained with Ss trained on a consistent reinforcement schedule. \section{METHOD}

The Ss were 20 male Sprague-Dawley rats, 80 days old at the start of the experiment. The Ss were trained in a straight runway that was $48 \times 4 \frac{112}{2} \times 6$ in. high, excluding the goalbox. The goalbox was $10 \times 412 \times 6$ in. and contained a copper foodcup, 2 in. in diam and $1 / 2$ in. deep. The runway floor was a bar grid.

All Ss were maintained on a 23 -h food-deprivation schedule and were given the foodcup on a $100 \%$ reinforcement schedule. They were confined in the goalbox for $30 \mathrm{sec}$ on all trials. The intertrial interval was approximately 30 min. Training was interrupted for 15 days, during which time the Ss were maintained on their regular 23-h deprivation schedule.

On the 24th day of the experiment, the Ss were given two warm-up trials. Running speed on the second trial was used to rank order the Ss. The slowest four Ss were discarded, and the remaining $16 \mathrm{Ss}$ were assigned to two groups according to a matched-groups design. The $S s$ in the experimental (E) group were placed directly into the goalbox, facing the foodcup, and were left for $30 \mathrm{sec}$. Within $15 \mathrm{sec}$ of removal from the goalbox, the Ss were placed in the start of the runway and were given their first test trial. Ss in the control (C) group merely ran their regular test trials without any direct goal placement. Four test trials were given, maintaining a $30-\mathrm{min}$ intertrial interval. The $S s$ in the two groups were run in a balanced order (ABBA).

\section{RESULTS AND DISCUSSION}

As indicated by Fig. 1, Ss in the E group ran faster over the four test trials than did the $\mathrm{Ss}$ in the $\mathrm{C}$ group. This difference was significant $(t=3.51, d f=7, p<.005)$. The results indicate that the facilitating effect of latent extinction, reported by Jones, Narver, \& Bridges (1967), is a reliable phenomenon. It should be noted that the results were essentially the same as in the earlier article, despite the fact that the Ss in the experiments differed in age and sex; the reinforcer was a sucrose solution in the present experiment and food pellets in the earlier experiment.

Jones, Narver, \& Bridges (1967) suggested that frustration becomes attached to the running response in the process of partially reinforced acquisition, and the strong frustration generated during the latent extinction placements serves to energize the running response. Since, in Experiment 1 of that article, the effect was still present $24 \mathrm{~h}$ following the placements, it would seem that the facilitation depends to some extent on a conditioned reaction that can reinstate arousal at a later time. Amsel's (1967) fractional anticipatory frustration $\left(\mathrm{r}_{\mathrm{f}}\right)$ could fulfill this role.

However, this interpretation requires that the distinctive stimuli $\left(\mathrm{s}_{\mathrm{f}}\right)$ produced by If would have to somehow become attached to the instrumental response prior to the first test trial. The Ss in the present experiment were given consistent reinforcement. Normally, Ss trained on consistent reinforcement should not be 


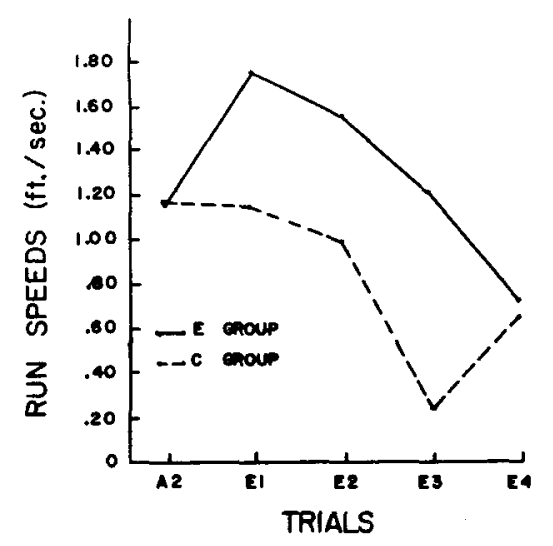

Fig. 1. Extinction performance of Ss receiving a latent nonreinforced placement (E group) or no placements (C group). Trial A2 was the last reinforced trial prior to the placement. Trials E1-E4 were the nonreinforced test trials.

frustrated and should not, therefore, learn to approach the goalbox in the presence of $r_{f}$-produced cues. However, the $S s$ were confined in the goalbox for a fixed period on each acquisition trial. If Ss finished eating early in the period, it is possible that frustration was aroused during the later portion of the confinement period. If so, then $r_{f}$ would have been present on subsequent trials (all of which were rewarded), and $s_{f}$ would have become attached to the instrumental response.

It remains to be explained why latent placements should generate greater magnitudes of frustration than do regular nonreinforcements. There is some reason to believe that frustration theory would predict the reverse. Amsel, Ernhart, \& Galbrecht (1961), for example, found that the magnitude of frustration was greater when a long runway preceded the first goal in a double runway. They assumed that the long runway gave Ss more time to generate strong $r_{g}$ prior to encountering nonreward. If Ss are placed directly into an empty goalbox, it seems that frustration theory would predict less, rather than more, frustration.

A parsimonious assumption that agrees with Amsel's (1967) theory and that seems to fit the present data is that facilitation occurred because the latent placements produced a mild increase in frustration. Specifically, it could be assumed that even when the instrumental response is not conditioned to $\mathbf{s}_{\mathrm{f}}$, a mild amount of frustration may enhance performance. Furthermore, similar to electrical shock
(Miller \& Davis, 1943), even strong frustration may facilitate rather than disrupt performance if frustration is introduced gradually. This condition may be met when a brief latent placement is interposed between acquisition and regular extinction.

If this interpretation is correct, then mild latent extinction operations may facilitate performance even when training involves consistent reinforcement.

\section{REFERENCES}

AMSEL, A. Partial reinforcement effects on vigor and persistence. In K. W. Spence and J. T. Spence (Eds.), The psychology of learning and motivation. New York: Academic Press, 1967. AMSEL, A., ERNHART, C. B., \& GALBRECHT, C. R. Magnitude of frustration effect and strength of antedating goal factors. Psychological Reports, 1961, 8, 183-186.

JONES, E. C., NARVER, R. L., \& BRIDGES, JR., C. C. A facilitating effect of latent extinction in a partial reinforcement situation. Psychonomic Science, 1967, 7, 23-24.

MILLER, N. E., \& DAVIS, M. A theoretical and experimental analysis of conflict behavior: IV. The influence of the positions of reward and punishment in the response sequence. In J. McV. Hunt (Ed.), Personality and the behavior disorders. Vol. 1. New York: The Ronald Press, 1944. 